Annual Report-March, 2005

Report Number DOE/NA/00069-1

Reporting Period: Dec. 15, 2003 to Dec. 14, 2004

DOE-NNSA Project DE-FG03-03NA00069

\title{
Micro and Nano-structure Development and Multiscale Physics at Sliding Metal Interfaces
}

\author{
PI: D. A. Rigney, The Ohio State University, \\ in collaboration with Los Alamos National Laboratory
}

\section{Introduction and Background:}

Much work has been reported on the response of ductile materials to high strain rates during impact. Separately, much work has been reported on sliding friction at various sliding velocities. This project is concerned with a combination of these conditions and the response of ductile materials to extreme loading conditions such as those involved in impact loading with sliding friction.

The work involves collaboration of the tribology group in Materials Science and Engineering at OSU and two groups at LANL, an impact loading group in the dynamic experimentation division and a computer simulation group in the applied physics division. The work includes impact and sliding tests, materials characterization and computer simulation. The two teams are investigating the same materials pairs: $\mathrm{Cu} / \mathrm{Cu}, \mathrm{Al} /$ stainless steel (SS) and $\mathrm{Ta} / \mathrm{Al}$. These were selected to allow comparison with the results of computer simulations at LANL and with sliding tests at OSU. The LANL team is providing impacted specimens for characterization at OSU. Both teams are performing molecular dynamics (MD) simulations to help guide and interpret the experimental work.

The project grant announcement was made on August 30, 2002. The award papers were received at OSU on February 3, 2003, with an official project start date of Dec. 15, 2002. The OSU team was assembled during autumn, 2002, and planning and preliminary work began before the official start date. The four members of the Los Alamos (LANL) team visited OSU on November 15, 2002, for a full day of discussions, lab tours and project planning. The first test samples were sent by LANL to OSU in December 2002. One member of the OSU team worked at LANL during the summer of 2003. The OSU team visited the LANL lab early in 2004, and one member returned for a more extended visit late in 2004.

\section{Project personnel:}

At OSU: D. A. Rigney, PI; K. Subramanian (post-doc); A. Emge and H. J. Kim (PhD candidates). H. J. Kim came to us with an M.S. in Materials Science and Engineering. He has passed the written and oral parts of our PhD candidacy exam. A. Emge came to us with a 
B.S. in Chemistry, so he still has some graduate core courses to take before he will be ready for the candidacy exam. Kim is focusing on the aluminum part of the project, while Emge is focusing on copper. K. Subramanian assists the two students with structural and chemical characterization, including TEM preparation and analysis. He is also involved in theory and computer simulations .

At LANL: P. Rightley (Mech. E.); J. Hammerberg (Physics, theory); P. Crawford (MSE). PR and PC have focused on the tests of impact with sliding; JH has focused on MD simulations of sliding for relevant materials pairs at different sliding speeds.

Coordination of OSU and LANL Teams: Coordination this year among the interdisciplinary team members has been accomplished via email, telephone, discussions at conferences and at a DOE workshop in Albuquerque, and by visits of Rigney, Kim, Emge and Subramanian to LANL. The next visits to LANL will take place when normal operations resume there. The shut down of LANL postponed other planned visits. However, in response to our petition, operations in the impact lab have recently resumed, and Emge was able to have an extended visit in Dec., 2004.

\section{Experimental Progress at LANL:}

The experiments at LANL involve an improved rotating barrel gas gun (RBGG) that allows independent control of impact velocity and sliding speed. The RBGG has the ability to provide consistent wave profiles having short rise times under high speed sliding and high impact load conditions, in the 'no sample' configuration (target rod and projectile only). Test results show that the mechanical joint configuration does not completely transfer the shear load through the joint interface, resulting in an incorrect depiction of the coefficient of friction behavior due to the impact and sliding event. More testing of this joint configuration must be done if it is to be used. The epoxy joint configuration appears to transfer the complete axial and shear load through the joint. However, the measured shear stress exceeds the specified maximum shear stress for the epoxy. This limits the sliding speeds that can be tested in this condition. Average values for the coefficient of friction of 0.5 for the no sample configuration agree with the numerous published data on copper/copper tribo pairs. The lower values for the epoxy and mechanical joint configurations suggest that the test configuration does have an effect on the coefficient of friction. The next step is to test the OFHC $\mathrm{Cu} / \mathrm{Cu}$ tribo pairs at various combinations of sliding speed and impact load to determine the behavior of the coefficient of friction. Other tribo pairs (Al/SS, Al/Ta) will be investigated in a similar fashion. Two tests performed at the extremes of the RBGG - low sliding and axial speeds, high sliding and axial speed - exhibited similar time average coefficients of friction of about 0.2 . The lower value may be a result of a lower surface roughness of the impact surface. Design of RBGG II-a second generation RBGG—is underway. This new design uses the same conceptual design with a different physical design approach. An air impulse turbine will be used as the mechanism for rotation of the barrel, allowing rotational sliding speeds of up to $350 \mathrm{~m} / \mathrm{s}(50,000 \mathrm{rpm})$.

Inspections that followed the LANL shut-down identified the need for some small changes in the RBGG facility. These changes have been made. They mainly involved covering electrical connections and providing proper documentation for all electrical components. No 
changes in the operation of the RBGG were needed.

Modifications in the target rod/projectile alignment system are in progress. These are designed to reduce or eliminate additional impacts after the initial impact. Also, a technician, J. Bainbridge, is being trained to do some of the testing work. This is expected to facilitate production of test specimens needed by the members of the OSU team for their characterization work.

\section{Experimental Progress at OSU:}

\section{Brief Summary of Experimental Progress at OSU:}

The OSU portion of this research project is focusing on the frictional behavior and structural changes in ductile FCC metals subjected to impact loading with sliding. The OSU group is examining the samples tested in LANL's novel RBGG and comparing them with samples produced at lower sliding speeds at OSU.

The experimental work at OSU focused on three tasks: (1.) designing and building an improved system for sliding tests at intermediate velocities, (2.) developing appropriate pretesting surface preparation and (3.) developing post-test characterization techniques. The new pin/disk wear testing system can achieve sliding speeds up to $1 \mathrm{~m} / \mathrm{s}$ in a range of environments and contact times as small as $0.1 \mathrm{~s}$. Resolution has been improved from $+/-7$ grams to better than +/- 1 gram. Transmission Electron Microscopy (TEM) was done on cross-sections of the as-machined annular OFHC copper samples. This revealed substructures consistent with extensive subsurface damage. These features would complicate our efforts to study the changes produced by impact with sliding. Samples should have a minimal amount of subsurface deformation prior to testing, so the deformation due to sliding will not be obscured. Therefore, a study was conducted to find a test specimen preparation method that would minimize subsurface deformation. Three machining methods were analyzed: lathe turning, fly-cutting and electrical discharge machining (EDM). Post-machining annealing at 275C for one hour in a vacuum furnace was also performed to remove deformation remaining from the machining processes. Microhardness was measured as a function of the distance from the machined surface. This was a simple way to determine the extent of subsurface deformation. The results show that annealed fly-cut samples are best for our purposes. Similar tests on pure aluminum samples suggest that annealing of fly-cut samples at 200C for an hour is sufficient to remove subsurface deformation.

Sliding tests with prepared copper specimens were performed in air at sliding speeds ranging from 5 to $50 \mathrm{~cm} / \mathrm{s}$. Steady state values of friction coefficient are similar for different velocities, but the sliding distance required to achieve steady state is longer at higher velocity. Also, at the highest speed, the steady state friction is lower, probably because of thermal effects. Material transfer was observed but mixing in of oxygen was not a major influence because test times were short. TEM revealed a nanocrystalline layer on the surface, as expected. Tests on aluminum were performed in both air and vacuum for a range of sliding speeds and normal loads, and samples were characterized by SEM/EDS, XPS and TEM. Oxygen progressively mixes into the deforming surface material and influences the evolution 
of surface chemistry, topography and friction. In vacuum, these effects are reduced and the friction is modified. It is higher than in air initially, but as sliding continues, the trend is reversed. Preliminary TEM results for short time testing show that the grain structure is refined through deformation and mixing. There is also evidence of a surface amorphous layer produced by sliding.

\section{Detailed Description of Experimental Progress at OSU:}

\section{Equipment Upgrades}

The existing pin-on-disc test apparatus was modified to improve the resolution and reliability of the normal load data acquisition system. The previous set-up consisted of a single strain gage in a quarter bridge configuration. The previous location of the normal load strain gage was close enough to the contact between the pin and disc that the strain gage output was suffering from thermal effects. This caused irregular loading profiles during tests. Two steps were taken to reduce this source of error. First, the pin holder was redesigned to increase its mass so that it will act as a heat sink between the contact area and the strain gages. A third pin mounting position was added to allow tests to be performed at higher velocities. Secondly, the quarter bridge strain gage was replaced with a half-bridge configuration. This has the advantages of increasing the resolution from $\pm 7 \mathrm{~g}$ to less than one gram, and also has the ability to cancel thermal effects. The normal load strain gage plate was also redesigned to increase the resolution of the normal load. This was done by moving the gages further from the contact area and by reducing the thickness of the plate.

\section{Los Alamos National Laboratory Visit}

Andrew Emge visited LANL in December 2004. During this extended visit he viewed the RBGG and became familiar with the set-up. He also took an electrical safety course that is required before he could be allowed to operate the RBGG. He also completed the required paperwork for a clearance level that would allow him to take additional required safety courses on the internet so he would not have to take them during future visits and would instead be able to focus on operation of the RBGG. Andrew also met with Paula and Kevin to discuss their plans for a next generation RBGG that would utilize air bearings and be capable of much higher rotational velocities.

\section{Surface Preparation Changes}

Additional surface preparation steps were added in order to remove machining marks from the flycutting process. After flycutting, the samples are mechanically polished sequentially with 400, 600, 800 and 1200 grit SiC polishing papers. After annealing, the surfaces are electropolished followed by ultrasonic cleaning in methanol. The samples are cleaned with compressed air prior to testing.

\section{RBGG Sample Characterization}

One pair of target and projectile rods was received from LANL in 2004. ${ }^{*}$ The pair was from a $\mathrm{Cu} / \mathrm{Cu}$ test at the minimum axial and rotational velocities. The projectile was spun at 1500 rpm and fired with a 20 psi plenum pressure. Optical and scanning electron microscopy did 
not reveal a clear wear track on the projectile or on the target. However, there were some circumferential scratches on the projectile. EDS showed a low amount of oxygen on the surfaces.

* Note: The shut-down at LANL stopped production of RBGG specimens for the second half of 2004 and into 2005. Several new specimens were produced during February and were received at OSU in early March 2005. These were produced at high impact and rotation velocities, so our expectation is that changes in the material will be more dramatic. The results from these tests will be described at the end of the next reporting period.

Pin-on-Disk Tests (Copper)

Oxygen free high conductivity (OFHC) copper disks were tested in sliding against 440C stainless steel balls. The tests were performed at varying sliding speeds ranging from $5 \mathrm{~cm} / \mathrm{s}$ to $50 \mathrm{~cm} / \mathrm{s}$ with contact times as short as 0.1 second. The tests were all performed in an air atmosphere. The applied load was held constant with a 200 g counterweight, which translates to roughly $100 \mathrm{~g}$ at the pin. The sliding times were adjusted to achieve a fixed sliding distance of $30 \mathrm{~m}$ for all tests. The rotational velocity of the disk is adjusted to achieve the desired sliding velocity before the pin is brought into contact so that initial transients can be measured.

Surface changes and deformation resulting from sliding were characterized with the use of scanning electron microscopy (SEM) and energy dispersive X-Ray spectroscopy (EDS). Deformation has been observed on the surfaces of both the pin and disk accompanied by material transfer from the disk to the pin. Subsurface deformation was studied with the use of Transmission Electron Microscopy (TEM). Focused Ion Beam (FIB) milling was used to prepare site-specific TEM foils from the wear track.

\section{Friction Data Analysis (Copper)}

Friction force results from four tests are shown in Figure 1. The steady state values are very similar for all but the highest velocity test, for which the friction force is lower. The main difference between the results for the three lower velocities is that the sliding distances required to achieve steady state values change with sliding velocity. From Figure 1 it can be seen that the distance required for steady state increases as the sliding velocity decreases.

\section{Characterization (Copper)}

Once the tests were performed, Scanning Electron Microscopy (SEM) with Energy Dispersive Spectroscopy (EDS) capabilities was used to characterize the sliding surfaces on both the pin and the disc. SEM and EDS results did not show material transfer from the pin to the disk, but did show material transfer from the disk to the pin as can be seen in Figure 2(a). This is expected as the pin is the harder of the two materials. EDS was also used to determine the extent of oxidation on the wear track on the disks. EDS detected only a couple of atomic percent oxygen on the wear track from each test.

The width of the wear track on the disks is very similar for all of the tests at about 300-400 $\mu \mathrm{m}$. A corresponding worn area could also be seen on the balls with a width very similar to that of 
the track on the disk. The wear track morphology varies with a change in sliding velocity. At the low velocity of $4.6 \mathrm{~cm} / \mathrm{s}$ the grooves in the wear track are almost entirely circumferential. As the sliding velocity increases, some of the grooves on the wear track turn away from the circumferential direction and move across the wear track as shown in Figure 3 from the 50 $\mathrm{cm} / \mathrm{s}$ test. These grooves are seen to increase in frequency as the sliding velocity increases.

Subsurface deformation of the worn disk surfaces was studied with Transmission Electron Microscopy (TEM). Focused Ion Beam (FIB) milling was used to prepare site-specific TEM foils from the wear track in the longitudinal direction. The TEM revealed a nanocrystalline layer that extends about $0.5 \mu \mathrm{m}$ below the surface (Figure 4). Below this layer is a heavily deformed region with larger grains.

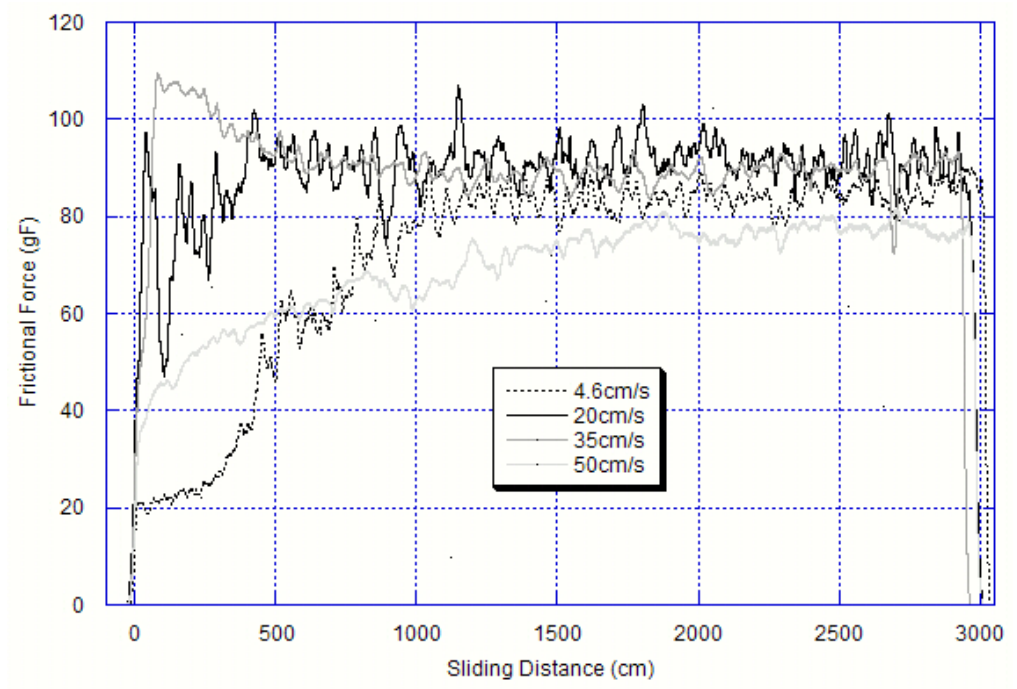

Figure 1: Friction force vs. sliding distance for four sliding velocities

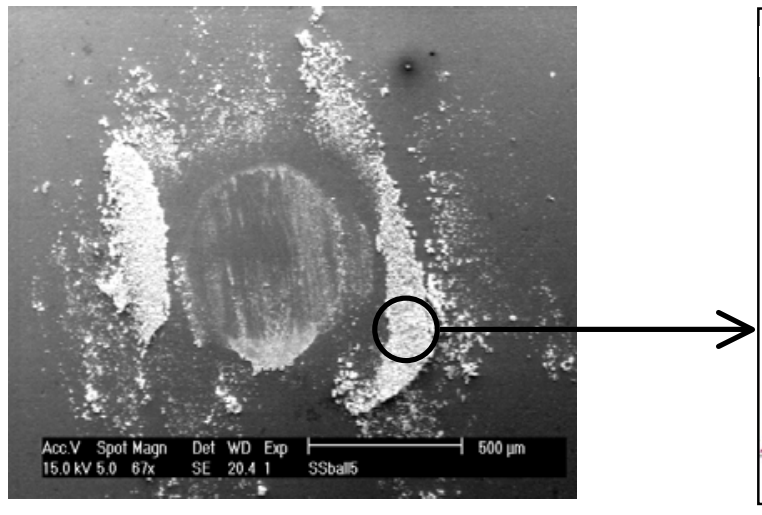

(a)

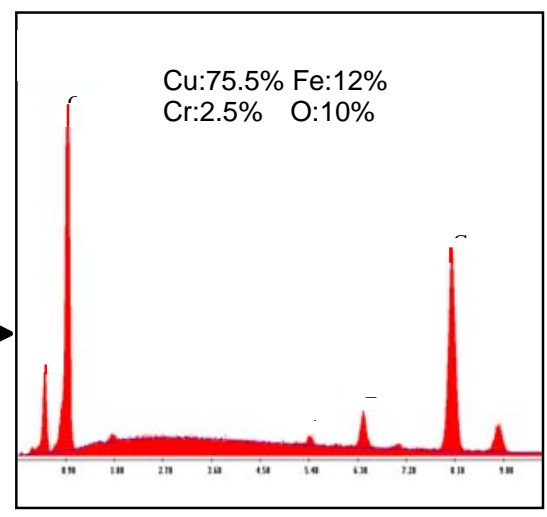

(b)

Figure 2: (a) SEM image of a 440C stainless steel ball after sliding against an OFHC copper disk at $4.6 \mathrm{~cm} / \mathrm{s}$ for 30 meters. (b) EDS of the wear debris shows a large percentage of copper signifying material transfer from the disk to the pin. 


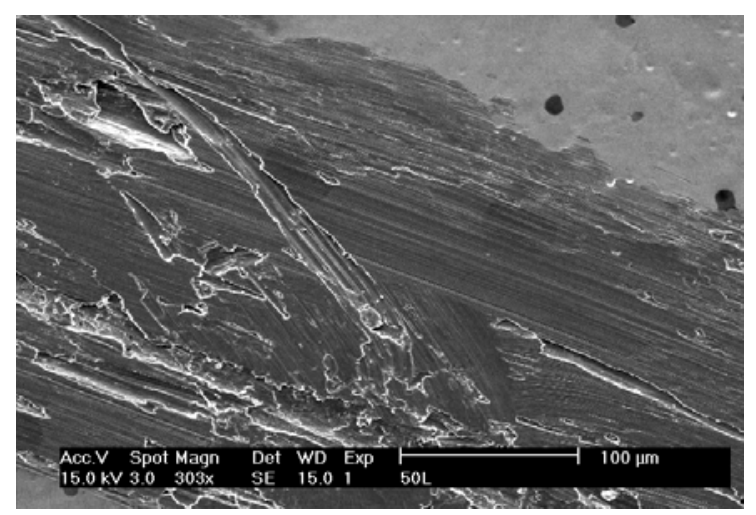

Figure 3: Wear track on an OFHC copper disk after sliding against 440C stainless steel at $50 \mathrm{~cm} / \mathrm{s}$ for 30 meters.

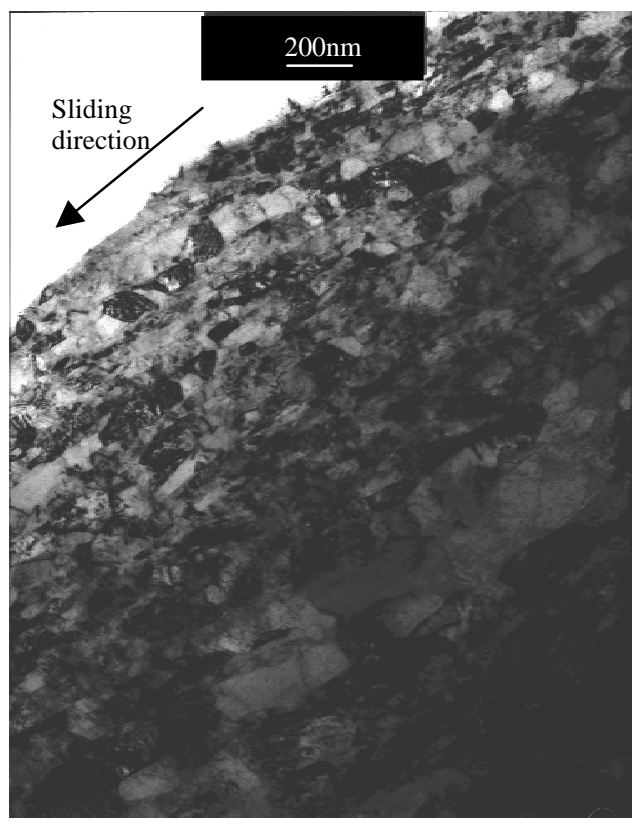

Figure 4: TEM image of OFHC copper sample showing a nanocrystalline region produced by sliding against 440C stainless steel in air.

\section{Sliding Tests (Aluminum)}

The improved tribometer can achieve sliding velocity up to $1 \mathrm{~m} / \mathrm{s}$ and with contact as short as tenths of a second. Therefore, the equipment can bridge the gap between the RGBB apparatus at LANL and the more conventional pin-disk tribometer. Sliding speeds ranged from $\sim 25$ $\mathrm{cm} / \mathrm{s}$ to $\sim 50 \mathrm{~cm} / \mathrm{s}$ and contact time was about 1 second. Normal load was increased to 150 $\mathrm{g}$, which is three times larger than used for earlier low speed tests. Vibrating of the arm system in the tribometer causes the data signal to oscillate as shown in Figure 5(a). After choosing a 
proper contact time, the signal was filtered by a numerical smoothing process. Figure 5(b) shows the processed signal. The processed experimental data are summarized in Figure 6. Microstructure characterization will be done next. As shown in Figure 6, frictional behavior is similar regardless of sliding speed in this range. Friction coefficient values are about 0.4 except during the initial and final transients. This is less on the average than the values obtained during long-time and low speed sliding tests. This is consistent with several authors' results, which indicate a reduction in the coefficient of friction when the normal pressure and/or the sliding velocity are increased.

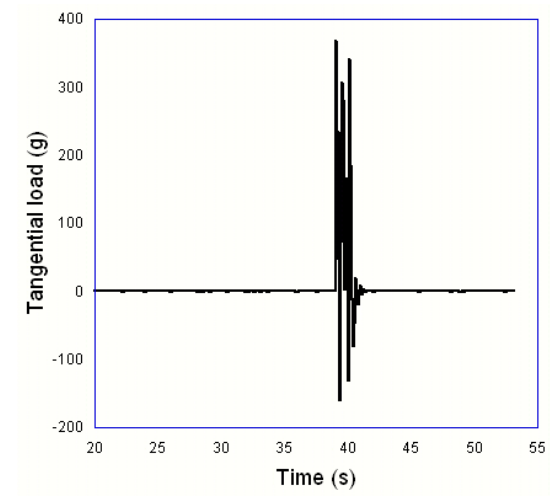

(a)

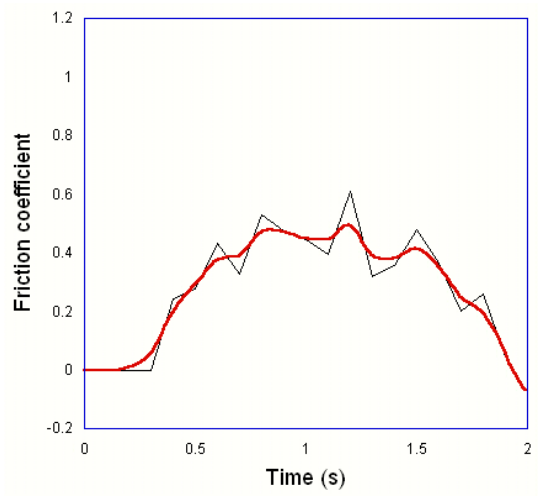

(b)

Figure 5: (a) Original tangential load signal and (b) friction coefficient after data processing
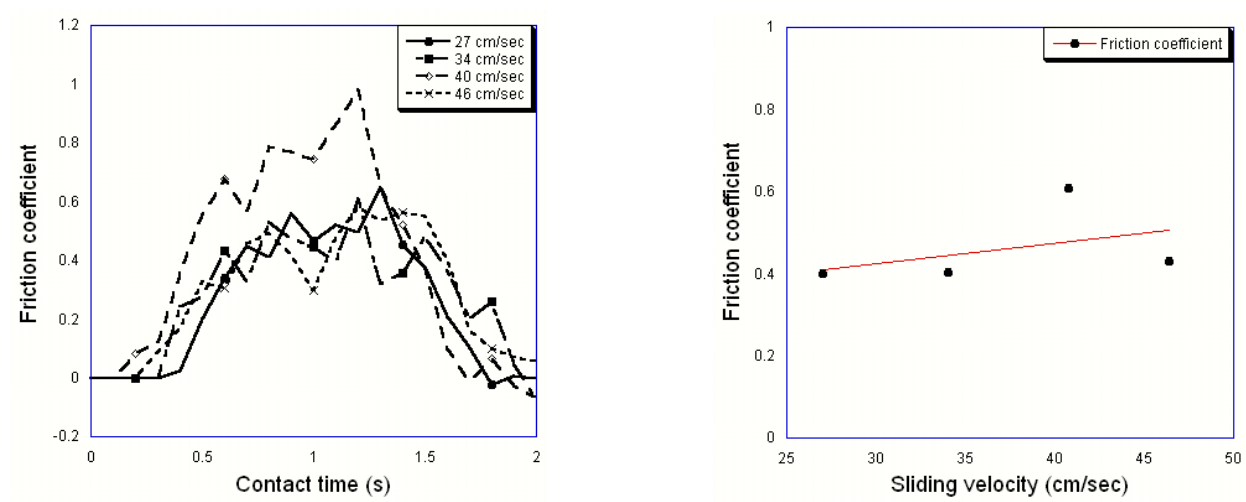

Figure 6: Friction coefficient for several sliding speeds

\section{Environmental Effects (Aluminum)}

Initial sliding tests were in air. Testing conditions were then extended to nitrogen and to air with lower humidity. After five hours of sliding, the wear surface and wear debris were characterized using SEM and EDS. Friction coefficients are shown in Figures 7(a) and 7(b) for different humidities. In both cases, the friction coefficient decreases at first and then increases. However, the time needed to reach the lowest value is not the same. With high humidity, the friction coefficient quickly decreased; at low humidity, the rate of decrease was much less. Sliding behavior is similar in vacuum and in nitrogen (Figures 7(c) and 7(d)). While tests in air showed distinctive regimes of friction, tests in vacuum and nitrogen showed more steady friction. 


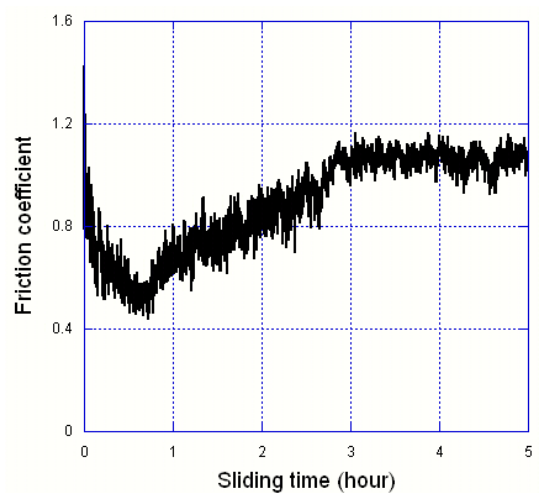

(a)

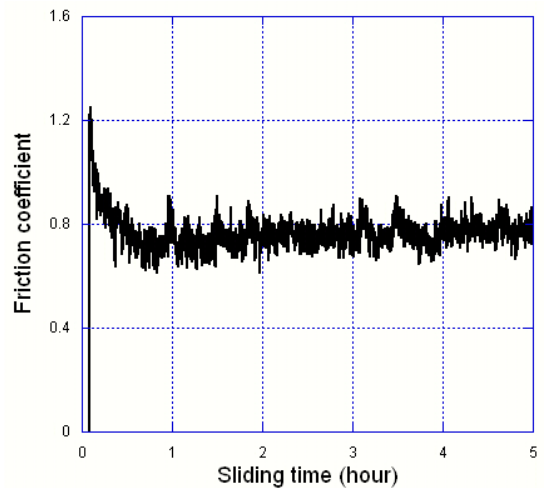

(c)

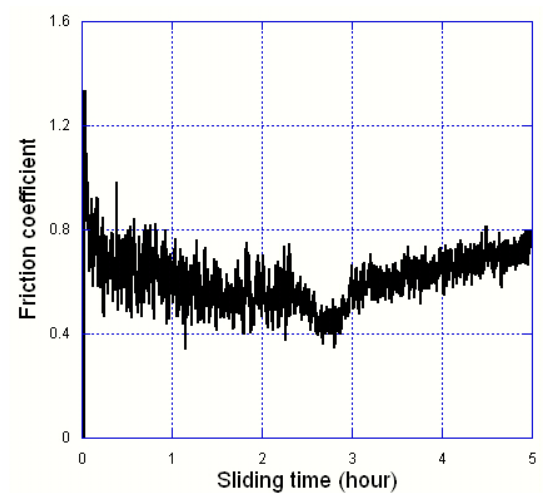

(b)

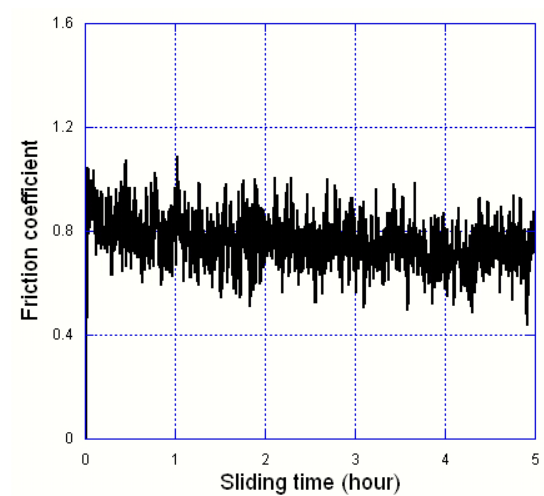

(d)

Figure 7: Friction coefficient for different environment tests. (a) Air and high humidity (RH=60\%) (b) Air and low humidity (RH=20\%) (c) Vacuum (d) Nitrogen

Figure 8 shows SEM images of the sliding surface for each case. Clear differences in wear track morphology are visible; they depend on the extent of oxidation. EDS confirms that more oxygen is incorporated in or on the surface for sliding with high humidity. The wear track width is the smallest for the vacuum environment test. The wear surface for the vacuum test shows smooth areas on the surface. After sliding in the nitrogen environment, the wear track morphology is very rough and the track width is larger than in the other cases. This is consistent with the large fluctuations observed in the friction force data.

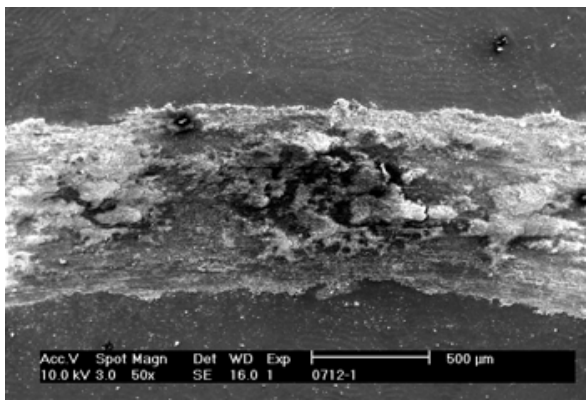

(a)

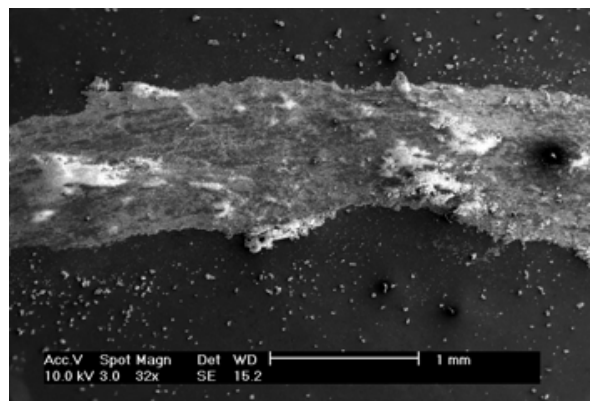

(b) 


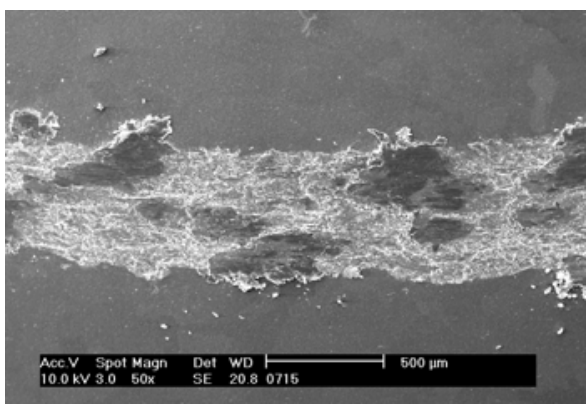

(c)

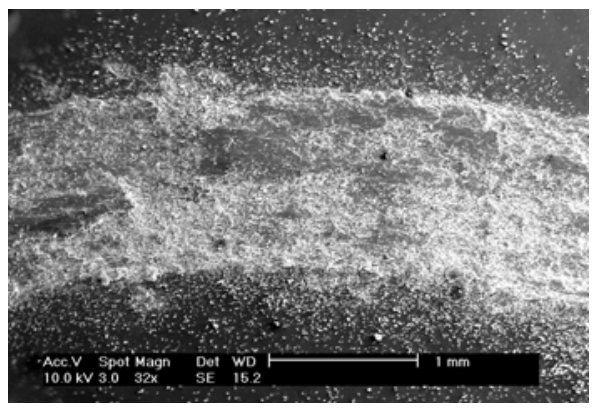

(d)

Figure 8: SEM images of wear track for different environment tests. (a) Air and high humidity (60\%) (b) Air and low humidity (20\%) (c) Vacuum (d) Nitrogen

In Figure 9, SEM images of wear debris are shown. The test in vacuum produced a very small amount of wear debris. The higher the oxygen level, the smaller the debris size is. In air tests, aluminum debris with more oxide ranges in size from a few tens of nanometers to micrometers.

There have been many proposed mechanisms of oxide particle debris formation. The model most widely used is based on growth of a surface oxide followed by removal of the oxide as debris. Earlier work in the OSU group has never shown support for this model. In general, the debris particles are mostly metallic with an intimate mixture of oxide, consistent with a mechanism involving mechanical mixing. Further characterization is needed to establish the mechanism operating in the present case.

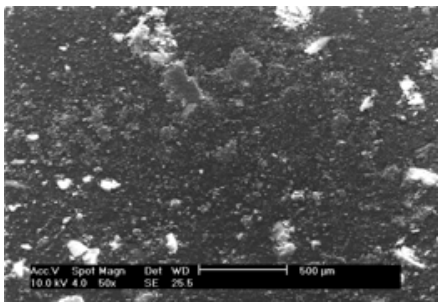

(a)

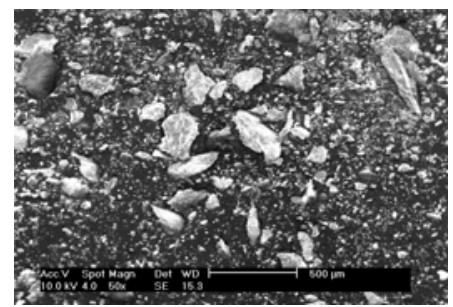

(b)

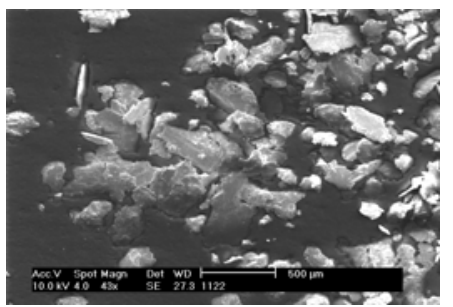

(c)

Figure 9: SEM images of wear debris for different environment tests. (a) Air and high humidity (60\%) (b) Air and low humidity (20\%) (c) Nitrogen

\section{Impact with Sliding (Aluminum)}

During the LANL shut-down we obtained samples of aluminum 5083 impacted with sliding at another laboratory. These specimens allowed us to check our TEM preparation techniques and to obtain preliminary information on structure changes.

Specimens were prepared for TEM first by Focused Ion Beam (FIB) and then by conventional thinning methods. Using FIB, we observed two distinct structures: a nanocrystalline region 
near the surface and more typical deformed structures further from the interface. However, FIB processing can lead to thermal effects that can modify the structure, especially in aluminum. Therefore we prepared another TEM foil by mechanical thinning, slurry drilling and jet polishing. Figure 10 shows a very highly deformed structure, even well below the surface.

FIB has the obvious advantage that it can produce foils with uniform thickness over a broad area, allowing convenient observation of cross-sections showing gradients of structure. However, because of thermal effects with FIB, our observations on these aluminum specimens suggest that conventional foil preparation techniques are less likely to modify the structure we want to study. Colleagues in another group at OSU have come to similar conclusions for their aluminum alloys.

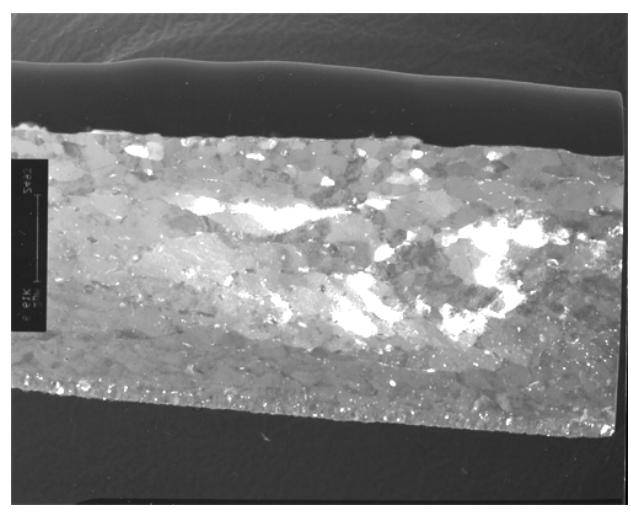

(a)

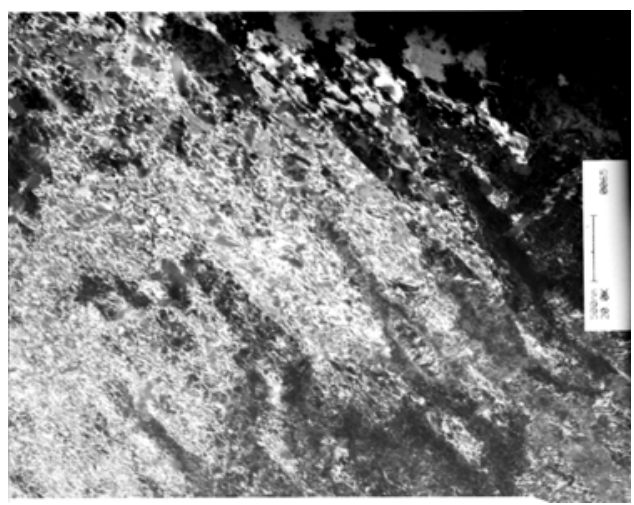

(c)

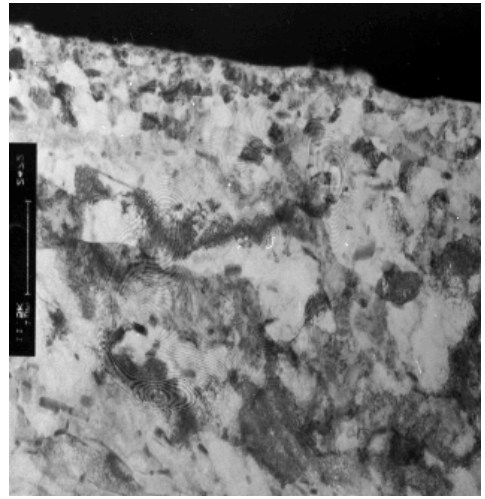

(b)

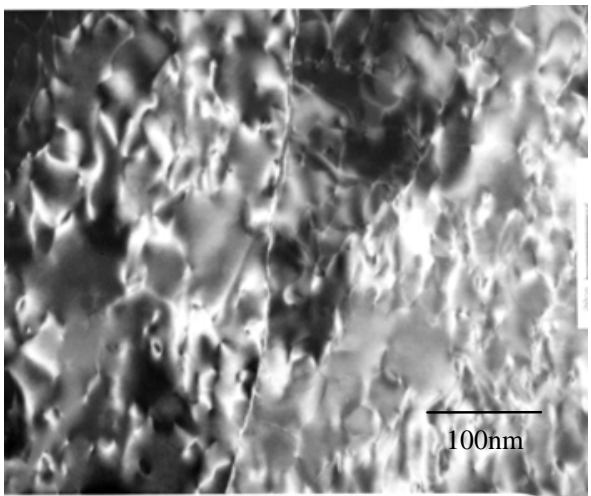

(d)

Figure 10: TEM micrographs: (a) dark fieled image of whole area of thin membrane; (b) bright field image of higher magnification; (c) highly deformed structure; (d) high magnification image of (c). 


\section{Impact of Recent Temporary Shut-Down of LANL:}

- $\quad$ The experimental part of the project being performed at LANL was suspended during the temporary laboratory-wide shut-down. This stopped the production at LANL of impacted specimens that the OSU group was prepared to characterize.

- In November 2004, we petitioned to have the relevant portion of the lab re-opened so we could proceed with tests of impact with sliding. The petition was approved by the Director of LANL and by a Deputy Director of DOE. Soon afterwards, the LANL part of the team was allowed to resume experimental work on the project. One of our students visited LANL during December. He received training and worked with the LANL team, but he was not authorized to perform impact tests. Since then, new specimens have been produced at LANL and mailed to OSU for characterization. With resumption of normal activities in the LANL lab, additional visits to LANL will be scheduled during 2005.

- $\quad$ Details of the Lab-wide shut-down and the restart process are presented in Appendix 1 of this report.

- The delays at LANL forced us to re-focus our efforts at OSU. Fortunately, the OSU group built its own high-speed sliding instrument as part of this project, so tests and analysis have continued with that system. Also, the post-doc was able to devote more time to the application of fluid mechanics and MD simulations to the sliding behavior of both amorphous and crystalline materials. The results are intriguing. They exhibit formation of eddies (vorticity), mechanical mixing and correlations with friction and mechanical properties. Further details of the simulation results are provided later in this report.

\section{Training:}

Previously, the students were trained in the use of OSU's XL-30 Environmental Scanning Electron Microscope (ESEM), Pad-V X-Ray diffractometer, pin/disk wear testing apparatus, transmission electron microscope (TEM) sample preparation techniques and other characterization tools. Also previously, the post-doctoral researcher was trained in the use of our dual beam Focused Ion Beam (FIB) instrument, which enables the preparation of sitespecific TEM samples. During the current reporting period, the students have been trained in the uses of the FIB instrument and received further experience with the TEM and with traditional specimen preparation involving electropolishing. The post-doctoral researcher has learned to do molecular dynamics (MD) simulations of sliding, to analyze the results in terms of vorticity, and to combine fluid mechanics ideas with strain rate sensitivity to predict flow behavior near sliding interfaces.

Degree status of the two graduate students (Kim and Emge) is given in the earlier section on Project Personnel. 


\section{Computer Simulations and Other Analytic Work:}

\section{LANL: Theoretical and Simulation Synopsis}

Theoretical work associated with this project has been carried out by J. Hammerberg and his collaborators at Los Alamos National Laboratory (LANL). They have developed a model of dry sliding which incorporates mechanisms of microscopic dissipation that depend on the regime of sliding velocity, $\mathrm{v}$, scaled by the transverse sound speed, $\mathrm{c}$, of the weaker of the interfacial materials. For low values of $\mathrm{v}, \mathrm{v} / \mathrm{c}<<1$, phonon mechanisms dominate and a linear response analysis leads to an initial increase in the frictional force with velocity for smooth interfaces. For higher velocities dislocation mechanisms become more important and for velocities $v / c \geq 1 / 10$, dynamically induced phase transformations occur resulting in a weakening of the frictional force with velocity and the formation of subgrain structure which may include local melting. In many cases the velocity dependence of the frictional force in this regime scales as $(\mathrm{v} / \mathrm{c})^{-\mathrm{a}}$, with $\mathrm{a}=3 / 4$. This theoretical and simulation background has been discussed in a series of publications and presentations. The constitutive theory of the frictional force outlined above is being compared with the experimental data that are being obtained in the pressure regime 0 to $5 \mathrm{GPa}$ and velocity range 0 to $100 \mathrm{~m} / \mathrm{sec}$. Part of the theoretical program is numerical simulation of the experimental configuration via macroscopic computer simulations based upon the model described above.

\section{OSU: Simulation and Theoretical Synopsis}

MD modeling at OSU began with simple amorphous materials to determine what features might be insensitive to details of structure. More recently the work has been extended to a simple crystalline network, with both smooth and rough interfaces. The presence of asperities affects the depth of the highly disturbed material. For both amorphous and crystalline cases, at high sliding speeds, the results suggest that the flow of material close to the sliding interface is characterized by the formation of eddies, intimate mixing and "diffusion-like" growth of the

mixed layer. Vortices are a few $\mathrm{nm}$ in diameter. These eddies are largely responsible for frictional energy dissipation and mechanical mixing. Two examples of vorticity maps are shown in Figure 11. 


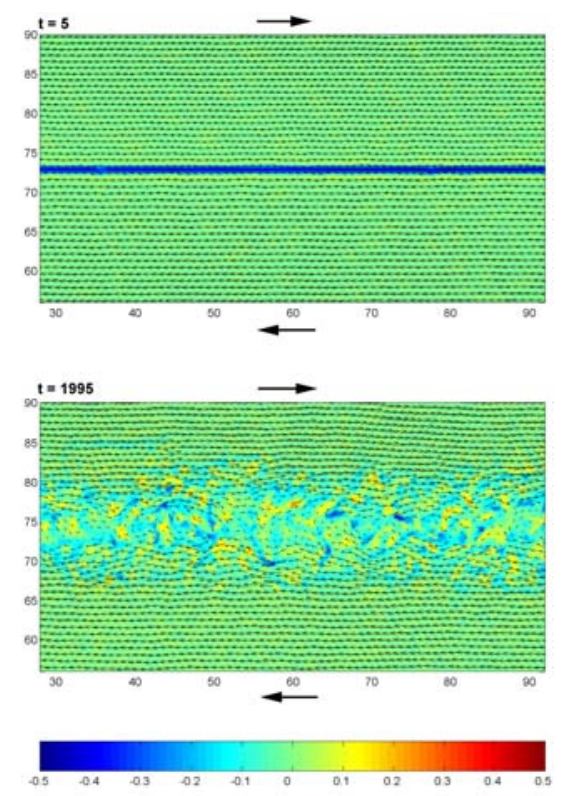

(a)

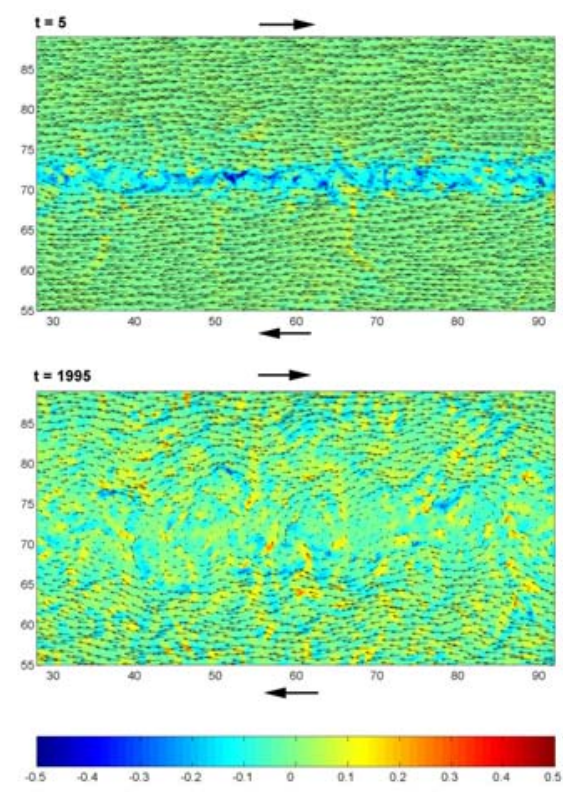

(b)

Figure 11a: Results from MD simulations of a model crystalline system A sliding on another crystalline system B at a relative velocity of 1.0 (Lennard-Jones units). Upper part of figure is at time $t=5$, while lower part of figure is at $t=1995$. Shading represents vorticity. Velocity vector plots show development of vortices at sliding interface.

Figure 11b: Results from MD simulations of a model amorphous system A sliding on another amorphous system B at a relative velocity of 1.0 (Lennard-Jones units). Upper part of figure is at time $t=5$, while lower part of figure is at $t=1995$. Shading represents vorticity. Velocity vector plots show development of vortices at sliding interface, with more extensive delocalization of vorticity than for the crystalline case.

The tribomaterial formed by vorticity is nanocrystalline or amorphous, depending on the system chosen. A comparison of eddy sizes with nanocrystal sizes in actual tribomaterial suggests that vorticity is directly responsible for the formation of such nanocrystal material. It is suggested that the flow of material near the interface is similar to that in fluids. The resulting eddies affect frictional energy dissipation and mechanical mixing. At lower sliding speeds the behavior is similar for amorphous materials but changes for crystalline materials. A shear-layer model of flow is qualitatively consistent with velocity profiles and friction behavior revealed by these MD simulations.

It is observed that the friction force is sensitive to velocity. This is attributed to the softening of the material due to localized heating resulting from sliding. This hypothesis is further supported by the concomitant attainment of steady state interface temperature and steady state friction. Flow properties appear to be highly sensitive to the temperature rise associated with frictional heating localized near the sliding interface. The response of crystalline and amorphous systems deviates at low velocities when crystalline systems with smooth interfaces do not undergo plastic deformation, thus leading to very low friction. This is in contrast to the behavior when asperities are present. 
In addition to the simulation work, the application of fluid flow equations has been investigated. Similarities between material flow during sliding and fluid flow under KelvinHelmholtz instability are recognized and have been exploited to derive analytical models for velocity, strain-rate, strain and temperature profiles across the interface. Knowledge of strainrate and strain profiles helps to define not only the region in which most of the deformation occurs, but also the rate of energy dissipation and the friction force. The analysis invokes momentum conservation principles and material flow laws to predict velocity profiles that develop during sliding. We assume a constant density and time-average flow only in the $\mathrm{x}$ direction. Momentum balance considerations yield an equation like a diffusion equation. An effective viscosity can be defined and a generic flow law for a Herschel-Bulkley fluid brings in strength parameters and strain rate dependence. The solutions involve a Gauss hypergeometric function that includes strain rate sensitivity, $\mathrm{m}$, as a materials parameter. The predicted velocity profile depends on the strain rate sensitivity, $\mathrm{m}$. The spatial extent of the deformed zone is determined by strain rate sensitivity, strength parameters and the imposed sliding velocity. These are very intriguing and perhaps important results that will be explored furtherand prepared for publication during the third year of the project. Examples are shown in Figure 12.

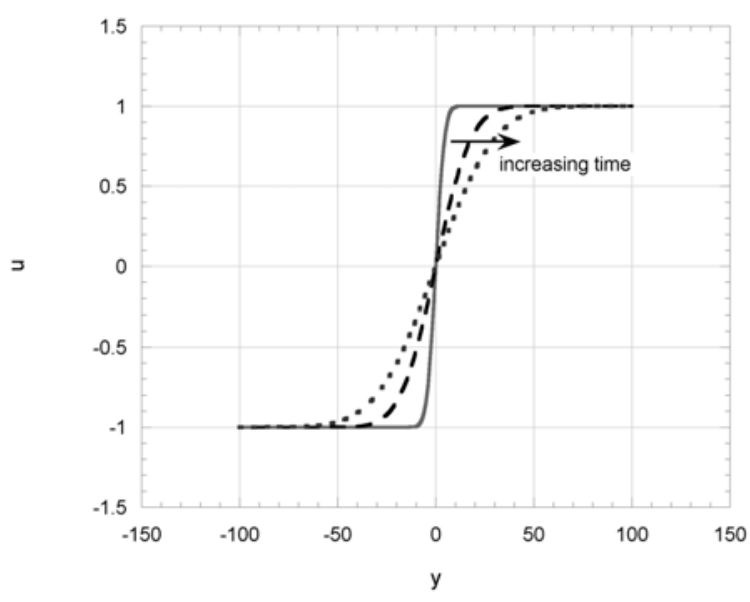

(a)

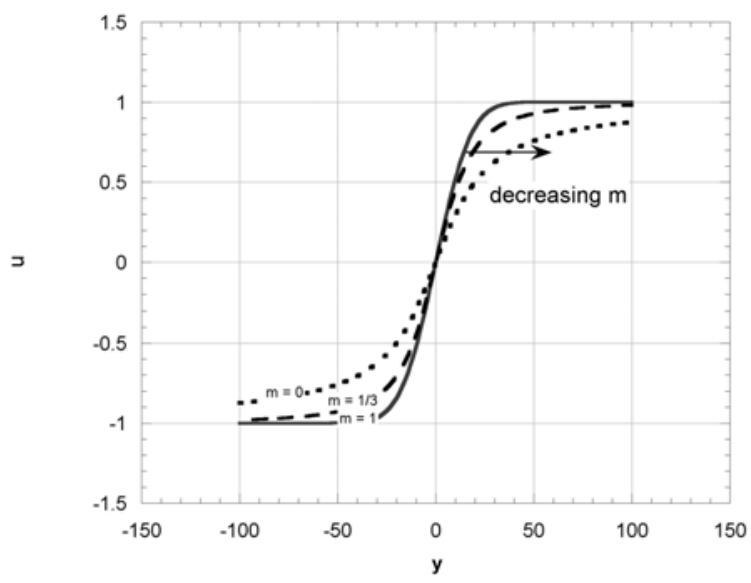

(b)

Figure 12a: Predicted velocity profile near the sliding interface $(y=0)$ for the case of strain rate exponent $\mathrm{m}=0.33$. The three curves show the spreading of the deforming material with time.

Figure 12b: Predicted effect of changing strain rate exponent $(\mathrm{m})$, with all other parameters held at the values used in Fig. 8a. Note that the actual velocity profile for $m=0$ will be step function, because an effective diffusion coefficient goes to zero as $\mathrm{m}$ goes to zero. For large $\mathrm{m}$, the spreading rate of the deformed material is proportional to $\mathrm{t}^{\wedge} 1 / 2$; for small $\mathrm{m}$ it is proportional to $t$. 


\section{Budget Comments:}

- $\quad$ The temporary shut-down at Los Alamos affected travel plans during 2004 ; therefore expenses for travel were less than expected. However, we anticipate that this is a temporary situation, because further visits of students to LANL during 2005 are planned to allow accelerated production of test specimens for characterization and analysis at OSU.

- $\quad$ DOE informed us earlier that $\$ 256,758$ is planned for this project for the third year. In December, 2004, $\$ 64,189.50$ of this was received at OSU. Assuming the remaining $\$ 192,568.50$ is received in a timely manner, we anticipate no budget difficulties.

\section{Publications/Presentations:}

[1.] K.Subramanian, J.H.Wu and D.A. Rigney, The Role of Vorticity in the Formation of Tribomaterial during Sliding, presented at Spring MRS Meeting, San Francisco, April 12-16, 2004; published as paper 9.6 in MRS Procs. Vol. for Symposium P, Nanoscale Materials and Modeling-Relations Among Processing, Microstructure, and Mechanical Properties, 2004.

[2.] James E. Hammerberg and Brad Lee Holian, Surface Modification and Mechanisms: Friction, Stress, and Reaction Engineering, G.E.Totten and H.Liang, eds.,(Marcel Dekker, New York, 2004), pp.723-749.

[3.] J.E. Hammerberg, R. Ravelo, T.C. Germann, J.D. Kress and B.L. Holian, Shock Compression of Condensed Matter-2003, M.D. Furnish, Y.M. Gupta, and J.W. Forbes, eds., (American Inst. of Physics, 2004), "Sliding Friction at Compressed Ta/Al Interfaces”, pp. 565568.

[4.] P. J. Crawford, K. N. Rainey, P. M. Rightley, and J. E. Hammerberg, 2003, "A Novel Experimental Technique for the Study of High-Speed Friction Under Elastic Loading Conditions," presented at the 13th American Physical Society Topical Conference on Shock Compression of Condensed Matter in Portland, OR, July 20-25, 2003, Proceedings edited by M. D. Furnish, Y. M. Gupta and J. W. Forbes, American Institute of Physics (2004), pp. 545548.

[5.] James E. Hammerberg, Timothy C. Germann, Brad Lee Holian, and Ramon Ravelo, MRS Symposium Proceedings, Vol. 821: Nanoscale Materials and Modeling - Relations Among Processing, Microstructure and Mechanical Properties, “ Nanoscale Structure and High Velocity Sliding at Cu/Ag Interfaces”, p.6.5.1-p.6.5.6(2004).

[6.] J.E. Hammerberg, B.L. Holian, T.C. Germann and R. Ravelo, Metall. And Mat. Trans. 35A, "Nonequilibrium Molecular Dynamics Simulations of Metallic Friction at Ta/Al and Cu/Ag Interfaces”, 2741-2745 (2004).

[7.] LANL Poster and presentation at DOE-NNSA workshop at Albuquerque, NM, March, 2004.

[8.] OSU Poster and presentation at DOE-NNSA workshop at Albuquerque, NM, March, 2004. [9.] James E. Hammerberg, Timothy C. Germann, Brad Lee Holian and Ramon Ravelo, 'Nanoscale Structure and High Velocity Sliding at Cu/Ag Interfaces', Mat. Res. Soc. Symp. Proc. Vol. 821, P.M.Anderson, T.Foecke, A.Misra and R.E.Rudd, eds., (Materials Research Society, Warrendale, PA), 103-108 (2004).

[10.] James E. Hammerberg and Brad Lee Holian, 'Simulation Methods for Interfacial Friction in Solids' in Surface Modification and Mechanisms: Friction, Stress and Reaction 
Engineering, G.E.Totten and H.Liang, eds., (Marcel Dekker, New York) 723-749 (2004). [11.] J.E.Hammerberg and T.C.Germann, 'Frictional Interactions at Compressed Cu-Ag Interfaces’, Plasticity-2005, Jan. 3-8, 2005, Kaua’i, HI.

[12.] H.-J. Kim, A. Emge, K. Subramanian and D. A. Rigney, Nanostructure Development Induced by Sliding Friction, Ohio Nanotechnology Summit, Dayton, OH, March 2-3, 2005.

[13.] K. Subramanian and D. A. Rigney, Molecular Dynamics Study of Tribological Phenomena at High Sliding Velocities, APS March Meeting, Los Angeles, March 22, 2005.

[14.] P. J. Crawford, P. M. Rightley and J. E. Hammerberg, A Study of High Speed Friction Behavior under elastic Loading Conditions, APS March Meeting, Los Angeles, March 22, 2005.

[15.] R. Ravelo, T. C. Germann and J. E. Hammerberg, High Density, High Velocity Sliding for Ta, Al Interfaces, APS March Meeting, Los Angeles, March 22, 2005.

[16.] H.-J. Kim, A. Emge, S. Karthikeyan and D. A. Rigney, Effects of Tribooxidation on Sliding Behavior of Aluminum, to be presented at Intl. Conf. on Wear of Materials, San Diego, CA, April 24-28, 2005, and published in Wear, 2005.

[17.] A. Emge, H.-J. Kim, K. Subramanian and D. A. Rigney, The Effect of Sliding Velocity on the Tribological Behavior of Copper, poster, to be presented at Intl. Conf. on Wear of Materials, San Diego, CA, April 24-28, 2005.

[18.] K. Subramanian and D. A. Rigney, Tribological Phenomena at High Sliding Velocities, poster, to be presented at Intl. Conf. on Wear of Materials, San Diego, CA, April 24-28, 2005.

[19.] LANL group plans to submit abstract to Shock Compression of Condensed Matter, APS Section Meeting, Summer, 2005.

[20.] LANL group plans to submit a paper on the $\mathrm{RBGG}(\mathrm{Cu} / \mathrm{Cu}, \mathrm{Cu} / \mathrm{SS}, \mathrm{Al} / \mathrm{SS})$ to a refereed journal by June, 2005 (consistent with a listed milestone for the friction project work package).

\section{Other Relevant Publications/Presentations:}

[1]. J.H.Wu, D.A. Rigney, M.L.Falk, J.H.Sanders, A.A.Voevodin, J.S.Zabinski, Tribological Behavior of WC/DLC/WS2 Nanocomposite Coatings, Intl. conf. on Metallurgical Coatings and Thin Films, San Diego, CA, April 19-23, 2004; to be published in Surface and Coatings Technology, 2004.

[2.] J.H.Wu, S.Karthikeyan (same as K.Subramanian), M.L.Falk, D.A.Rigney, Tribological Characteristics of Diamond-like Carbon (DLC) Based Nanocomposite Coatings, to be presented at Intl. Conf. on Wear of Materials, San Diego, CA, April 24-28, 2005, and published in Wear, 2005. Also, J.H.Wu attended Gordon Research Conf. on Tribology , Bristol, RI, June 27-July 2, 2004, and presented poster on related topics.

[3.] D. A. Rigney, invited as Keynote Speaker for the International Symposium on Forefront of Tribology, May 28-29, 2005, Kobe, Japan, “The Third Body Concept Updated: Plastic Flow, Accommodation of Shear, Velocity Profiles, Vorticity, Mechanical Mixing and Sliding Behavior."

[4.] D.A.Rigney invited as Keynote Speaker for the Symposium on Atomistics of Friction and Its Application for Nanotechnology, Intl. Tribology Conf. (ITC), Kobe, Japan, 2005. Authors: D.A.Rigney, J.H.Wu, K.Subramanian, M.L.Falk, What Can Simulations Tell Us about Tribophenomena in Real Materials? 


\section{Appendix 1}

Lab-Wide Shut-Down of LANL and Restart Process

a. A Lab-wide shutdown of all work occurred on July 15, 2004. All work was given a 'risk level' and all work in DX division was declared 'risk level 3' - the highest level. To be cleared to each level required addressing safety and security issues, as determined by the lab Management Self-Assessment. For level 3 activities, a Laboratory Readiness Review involving LANL and DOE/NNSA oversight was required.

b. Nov 10, 2004. A memo drafted by OSU and the LANL team members was sent to the DX Division Leader. This memo detailed the urgency to restart the RBGG project.

c. Nov 17, 2004 DX-3 Group Leader performed a safety walk-down of the RBGG Friction Laboratory.

d. Nov 19, 2004 DX Division Leader (Acting) performed a safety walk-down of the RBGG Friction Laboratory.

e. Nov 22, 2004 C-ADI Group Leader (Acting) performed a safety walk-down of the RBGG Friction Laboratory.

f. Nov 23, 2004 DX-division Waste Management coordinator performed a chemical/hazardous waste review of the RBGG Friction Laboratory.

g. As a result of the memo sent to the DX division management, it was decided to request a Level 0/3 Exemption, which would allow the operation of the RBGG Friction Lab as an "essential activity". This memo was initiated on Nov 22, 2005. After many revisions, the memo was sent to the Resumption Review Board (RRB). The RRB sent a recommendation to approve the request to the LANL Director and the Los Alamos Site Office of the NNSA on Dec 2, 2005.

h. Paul Rightley was informed of the approval of the Level 0/3 Exemption request by the LANL Director and the LASO on Dec 23, 2005.

i. Unfortunately, the holidays prevented any work from being conducted until Jan 1, 2005.

j. On Jan 24, 2005. Paula Crawford was converted to a regular staff member. As a result, work on the RBGG Friction project would become somewhat limited. This is due to the increased overhead cost of staff members as compared to post-docs.

k. Once the operation of the RBGG resumed, P. Crawford and P. Rightley worked to ensure smooth operation and collection of data. 
l. Official collection of data was begun during the last half of Feb 2005.

m. Normal operation of the RBGG facility most likely will be restarted through the DX Division resumption process by the end of March 2005. 